\title{
ФАКТОРЫ, ОБУСЛОВИВШИЕ НЕОБХОДИМОСТЬ РАЗВИТИЯ УГОЛОВНОЙ ПОЛИТОЛОГИИ
}

\begin{abstract}
Аннотация: Данная статья представляет собой комплексный анализ воздействия политического, экономического, сочиального, международно-правового факторов на принятие уголовно-правовых решений. Рассматривается вопрос разработки уголовной политики, для снижения принятия бессистемных, фрагментарных уголовно-правовых решений. Делается акцент на необходимость развития уголовной политологии как самостоятельной науки, разработка которой должна опираться на традищии российской уголовно-правовой науки с использованием теоретико-инструментального подхода, сложивщегося в системе уголовно-правовых наук. Говорится, что тенденции развития норм уголовного закона, регулирующих отношения в сфере экономики направлены на минимизацию уголовно-правового воздействия на субъекты экономической деятельности. В рамках данной работь, больший интерес представляет воздействие соииума на принятие уголовно-правовых решений, следовательно, на уголовное законотворчество. Применение уголовного права влечет в определенном смысле куда более значимые последствия для общества и личности, чем применение иных правовых отраслей. Оно связано с жизненно важными интересами и представляет собой непосредственное осуществление власти в самом жестком виде - в виде запрета и насилия.
\end{abstract}

Abstract: This article includes complex analysis of the influence of political, economic, international legal factors on the decision-making in the sphere of criminal law. The author discusses the issues of development of criminal policy in order to avoid passing non-systemic, fragmented criminal law solutions. The accent is made on the need to develop criminal political science as an independent science, which should be based upon the traditions of the Russian criminal law science and use the theoretic and instrumental approach, as it was formed within the system of criminal law sciences. It is stated that the tendencies of development of norms of criminal law regulating the relations in the sphere of economics are aimed at minimizing criminal law influence upon the economic subject. Within this article the author pays attention to the influence of society upon decision-making in the criminal sphere, and on criminal law-making in particular. Application of criminal law norms has consequences, which in some sense may be more significant than in any other branch of law. It is related to the vital interests and it is an expression of power in its strictest form-via prohibition and coercion.

Ключевые слова: уголовная политика, уголовная политология, уголовно-правовая мысль, уголовное законотворчество, законодательная иничиатива, социальный фактор, экономический фактор, международно-правовой фактор, политический фактор, модернизачия уголовного закона

Keywords: criminal policy, criminal political science, criminal legal thought, criminal law-making, legislative initiative, social factor, economic factor, political factor, modernization of criminal law.

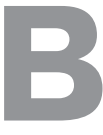

ч. 1 ст. 2 Уголовного Кодекса РФ законодательно закреплены объекты уголовно-правовой охраны. Для того чтобы эффективно выступать регулятором указанных общественных отношений, защищать правовые блага, обеспечивать законность функционирования норм и институтов, действие которых урегулировано другими отраслями, необходимо постоянное комплексное взаимодействие уголовного права и указанных сфер деятельности государства и общества. Формирование, развитие, практика применения уголовного закона на современном этапе развития Российской правовой системы зависит от многих факторов. Основными из них являются: политический, экономический, социальный, международно-правовой. Однако следует уяснить, что наряду с влиянием, которому подвержено общество со стороны уголовного закона, уголовное право, в свою очередь, претерпевает колоссальное воздействие. Эта двусторонняя связь не 
DOI: 10.7256/1811-9018.2013.12.10394

При цитировании этой статьи сноска на dоі обязательна

\section{Право и политика 12 (167) • 2013}

может расцениваться однозначно, так как вопрос о том, что именно должно подвергаться большему влиянию остается открытым. На наш взгляд, изменения, которые претерпевает уголовный закон, безусловно, должны соответствовать реалиям современного государства, однако уголовный закон должен быть более фундаментален и статичен. Принятие нормы под конкретное деяние или политическая статья подрывают общую концепцию уголовного закона. Целью данной статьи является анализ вышеуказанных факторов, в той или иной мере влияющих на уголовный закон, что позволит дать ответы на поставленные вопросы и решить ряд задач.

Социильный фактор. Уголовное право, представляющее собой одновременно специфический инструмент и сферу социального управления, подвержено определенному влиянию и со стороны социальных процессов проистекающих в обществе 1 . В рамках данной работы, больший интерес представляет воздействие социума на принятие уголовно-правовых решений, следовательно, на уголовное законотворчество.

В границах объективных возможностей и общества, и уголовного права задачи последнего адаптируются к социальным процессам, а само уголовное право направляется обществом, на удовлетворение признанных или признаваемых потребностей, когда конкретно определяются сфера действия, методы, тяжесть репрессии, отграничение от частного права и пр. На основе анализа реалий функционирования системы уголовной юстиции эти задачи превращаются в управленческие решения, поскольку они необходимы и возможны.

Ввиду этого стоит раскрыть понятие уголовноправовой мысли. Уголовно-правовой мыслью следует считать ряд суждений об уголовном праве, не всегда верных по своей сути, но оказывающих воздействие на закон. Причем данные суждения чаще касаются не уголовно-правового законодательства в целом, а единичных норм и практики их применения. Как правило, законодатель чаще прислушивается к мнению электората, нежели к разработанным концепциям уголовно-правовой науки. Это приводит к решениям, не всегда соответствующим задачам уголовного закона, однако данная политика законодателя находит одобрение в обществе ${ }^{2}$. Невысокий уровень правовой культуры среди населения страны говорит о том, что принимаемые таким образом нормы вряд ли будут в

\footnotetext{
${ }^{1}$ Жалинский А.Э. Уголовное право в ожидании перемен: теоретикоинструментальный анализ. - М.: Проспект, 2008. С. 5.

${ }^{2}$ См. подробнее: Уголовное право. Т.1. Общая часть / Под ред. д-р юрид. наук, проф., засл. деятеля науки РФ А.Э. Жалинского. - М.: Изд. Дом «Городец», 2011. - 864 с.
}

полной мере соответствовать принципам уголовного права, правовым и экономическим интересам всех слоев общества.

Экономический фактор. По единому мнению специалистов, в сфере экономики, как минимум, необходимо исходить из того, что уголовное право является вторичным (или дополнительным) к иным отраслям права доводом государства ${ }^{3}$. Криминализация деяния, а затем применение уголовного закона требую наличия некоторых дополнительных криминообразующих обстоятельств. К ним в рассматриваемой сфере относятся: выход хозяйственной практики далеко за пределы разумного его ведения, отсутствие возможности возмещения причиненного этой практикой вреда и пр.

На сегодняшний день ведется активная деятельность по внесению изменений в Главу 22 УК РФ. Наряду с социальной, экономическая сфера деятельности одна из наиболее динамично развивающихся. Совершенствование законодательства в области борьбы с преступлениями в сфере экономической деятельности ведется активно и направлено на предоставление большей свободы субъектам возникающих отношений, о чем может свидетельствовать декриминализация отдельных преступных деяний, снижений санкций, утрата деянием общественной опасности. В качестве примера приведем анализ ч. 1 ст. 169 УК РФ. Практика применения данной нормы практически отсутствует, о чем свидетельствуют статистические данные. Это может быть связано как с высокой латентностью данного преступления, так и трудностями доказывания выполнения субъектом объективной стороны преступления. По мнению автора, общественная опасность данного деяния невелика, при этом есть достаточно административно-правовых и гражданско-правовых средств противодействия явлениям, предусмотренным данной нормой. В свою очередь общественную опасность представляется возможным отразить в законе в виде крупного ущерба, переведя данный состав преступления из формального в материальны.

Тенденции развития норм уголовного закона, регулирующих отношения в сфере экономики направлены на минимизацию уголовно-правового воздействия на субъекты экономической деятельности. Исключение наказания в виде лишения свободы из ряда санкций норм представляется как конструктивное соглашение между государством и предпринимателем, с целью обеспечения эффективного и взаимовыгодного «сотрудни-

\footnotetext{
${ }^{3}$ Жалинский А.Э. Уголовное право в ожидании перемен: теоретикоинструментальный анализ. - М.: Проспект, 2008. С. 275.
} 
DOI: $10.7256 / 1811-9018.2013 .12 .10394$

При цитировании этой статьи сноска на dоі обязательна

Закон и правопорядок

чества» в данной сфере деятельности. Однако, на наш взгляд, сделать вывод о том, что сложившаяся ситуация представляет собой последствие влияния экономики на уголовное право однозначно, нельзя.

Международно-правовой фактор. Интеграция России в мировое сообщество усиливается с каждым годом. На современном этапе развития взаимодействие на мировом уровне в сфере экономики, политики не может осуществляться без приведения норм отечественного законодательства в соответствие с международным правом.

По смыслу Венской Конвенции о праве международных договоров от 23 мая 1963 г. $^{4}$, акты международного права закрепили дуалистическую теорию соотношения международной и национальной правовых систем. Эта теория на практике сводится к следующему: если влияние норм внутреннего права можно назвать первичным (так как государство исходит при создании норм международного права из положений собственного законодательства), то при наличии уже действующих правовых норм международного характера оно не может не признавать их преимущественного значения над нормами внутреннего права ${ }^{5}$. В случае юридического конфликта приоритет отдается норме международного права. Такое понимание соотношения двух правовых систем - международной и внутригосударственной нашло законодательное оформление как в Конституции РФ (ч. 4 ст. 15), так и в Уголовном кодексе РФ.

В последнее время все больший интерес представляет сравнительный-правовой анализ норм уголовного закона, практика и особенности применения отдельных статей и их наличие, либо отсутствие в системе уголовного права зарубежных стран. Это в свою очередь помогает выявить положительный опыт зарубежных стран в вопросах регулирования той или иной деятельности, применить полученные знания на практике, а именно при реформировании отдельных отраслей права, и уголовного права в частности.

Политический фактор. Стоит обратить внимание на то, что уголовно-правовое законодательство эволюционирует в непосредственной связи с изменениями в расстановке политических сил как в государстве, так и на мировой арене. Однако для комплексного понимания этого процесса необходимо уяснить данную взаимосвязь.

\footnotetext{
${ }^{4}$ Ведомости Верховного Совета СССР. - 1986. - № 37. - Ст. 772.

${ }^{5}$ Кибальник, А. Г. Влияние международного уголовного права на российское уголовное право :Автореф. Автореф. дис.... канд. юрид. наук. 12.00.08. Институт государства и права Российской академии наук. -М.,2003. -52c.
}

Политические факторы воздействуют на принятие уголовно-правовых решений по многим направлениям: а) законотворческие процессы, особенно в отношения внесения изменений и дополнений в действующий УК РФ (что является наиболее наглядным проявлением); б) реализация уголовной ответственности, в частности проявляющаяся применительно к «громким» делам и рутинным делам, ускользающим от внимания общественности; в) организационные (реформирующие современную систему борьбы с преступностью) меры. По любому из названных направлений можно видеть сферы и тенденции влияния, субъектов воздействия и т.п. Но в целом здесь следует учитывать общий (федеральный) и специальный (региональный) уровни, на которых политические факторы проявляются по-разному. Проблема более чем сложна и не может быть решена в рамках традиционных подходов, разработанных в науке уголовного права и таком ее разделе как уголовная политика. Поэтому обратимся к концепции уголовной политологии.

Практика применения уголовного закона очень часто зависит от имеющихся значимых политических факторов: расстановка политических сил в стране/peгионе, наличие активно действующих общественных объединений, организаций, их статус и авторитет.

Понятно, что в регионах, наиболее сильно испытывающих воздействие проявления экономического кризиса, безработицы, иных негативных социальноэкономических, экологических факторов сложнее, если вообще возможно выделить вектор и результаты воздействия политических факторов на принятие уголовно-правовых решений.

Естественно, что каждый субъект законодательной инициативы, выступая с законодательной инициативой, пытается обеспечить законность и правопорядок применительно к специфическим условиям и обстоятельствам (богатство природных ресурсов, интенсивность их использования, ослабление контроля со стороны центра). Но главное - это состояние преступности и готовность действующих на ее территории политических сил к определению приоритетов борьбы с преступностью, выделению финансовых, организационных, интеллектуальных ресурсов для борьбы с ней.

Анализирую состояние современного уголовного законодательства можно сделать вывод, что оно пластично, меняется и развивается в соответствии с потребностями общества и государства. Однако иногда является и манипулятором политической власти. В связи с этим та легкость, с которой вносятся поправки в УК РФ, не может не вызывать определенных опасений. 
DOI: $10.7256 / 1811-9018.2013 .12 .10394$

При цитировании этой статьи сноска на dоі обязательна

\section{Право и политика 12 (167) • 2013}

Уголовная политика. Все вышеперечисленные факторы должны непосредственно учитываться при разработке уголовной политики государства.

В науке проблемам уголовной политики уделялось значительное внимание, так как она всегда отражала очередной политический этап в развитии Российского государства. Причем интерес к уголовной политике то усиливался, то ослабевал в зависимости от содержания политических процессов, проходивших в обществе

В данной работе уголовная политика рассматривается как политика уголовно-правовая, а именно та часть или направление государственной политики в сфере борьбы с преступностью, которая реализуется средствами и методами только уголовного права. Вопрос разработки уголовной политики и следование намеченному курсу в современном государстве стоит остро. Генеральный прокурор России Юрий Чайка, выступая на парламентских слушаниях в Совете Федерации на тему «Совершенствования законодательства в сфере уголовно-правовой политики», обратил внимание на то, что «современное состояние уголовно-правовой политики характеризуется отсутствием четко обозначенной

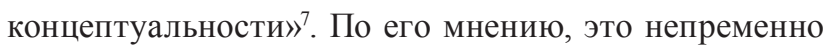
приводит к многочисленным непоследовательным и противоречивым изменениям, которые претерпевает уголовный закон. Подобное заключение можно сделать на основе комплексного анализа поправок в Уголовный кодекс РФ 1996 г. С момента принятия в закон было внесено более 700 поправок. За период 2011-2013 гг. Федеральными законами изменены более чем 150 статей УК РФ $\Phi^{8}$. Введен ряд новых составов преступлений. Некоторые нормы, как например ст. 129 УК РФ, были декриминализированы, но вновь находили свое отражение в уголовном законе, что может напрямую свидетельствовать об отсутствии конкретной концепции внесения поправок в Уголовный кодекс РФ. В связи с чем, Генеральный прокурор РФ считает, что «для начала необходимо разработать концепцию уголовной политики», а также создать совет при президенте РФ с участием ученых, сотрудников правоохранительных органов, судей и т.д. Это позволит рационализировать

\footnotetext{
${ }^{6}$ Г.Ю. Лесников. Проблемы соотношения уголовной политики и уголовного права // Научные ведомости Белгородского государственного университета. Серия: Философия. Социология. Право. №4. -2008 . C. 74.

${ }^{7}$ URL:http://www.vz.ru/news/2013/11/18/660179.html

${ }^{8}$ Barysheva $K$. Ways of the modern criminal law development. Justitias Welt. Ausgabe 22, November 2013 http://justitiaswelt.com/Aufsaetze/ AS86_201311_KB.pdf
}

уголовное законодательство и избежать, возможно, злоупотреблений правом, манипуляции уголовным законом. В качестве примера зарубежного опыта можно привести Отдел криминальной политики входящий в состав Министерстве Юстиций Эстонии, основными задачами которого является подготовка уголовно-политических решений. Отдел разрабатывает решения, на основе исследований и анализа изменений ситуации в стране, проводит статистический анализ совершенных преступлений, выявляет факторы, влияющий на предупреждение преступности. Это способствует тому, что все криминально-политические шаги основываются на достоверной информации.

Как один из вариантов решения проблемы «противодействия фрагментарному законодательству» заместитель председателя Верховного суда РФ А. Толкаченко видит значительное сокращение числа субъектов законодательной инициативы. Право законодательной инициативы в соответствии со ст. 104 Конституции РФ принадлежит Президенту РФ, Правительству РФ, депутатам Государственной Думы и членам Совета Федерации Федерального Собрания, законодательным (представительным) органам субъектов Федерации, а также Конституционному Суду, Верховному Суду, Высшему Арбитражному Суду РФ по предметам их ведения. Однако субъект законодательной инициативы только вносит предложение. Решение вносить изменения, либо нет, ему не принадлежит. Во-первых, изменение числа субъектов законодательной инициативы приведет к снижению в большей степени влияния социального и политического факторов на уголовное право. Зависимость между уголовным законом и иными сферами деятельности однозначна, однако вопрос целесообразности, продуктивности и эффективности данной зависимости остается открытым. Необходимость и степень абстрагирования уголовного права от перечисленных факторов требует детального анализа как законодательства в целом, так и практики его применения. Во-вторых, как указывалось выше, субъекты законодательной инициативы стремятся обеспечить законность и правопорядок применительно к специфическим условиям и обстоятельствам, соответствующим географическим, политическим, экономическим, социальным особенностям, могут выражать общее мнение определенных групп граждан и пр. Следовательно, подобное ограничение может непосредственным и не самым благоприятным образом сказаться на реализации задач уголовного права, механизмах уголовно-правового регулирования и т.д. 
DOI: $10.7256 / 1811-9018.2013 .12 .10394$

При цитировании этой статьи сноска на dоі обязательна

Закон и правопорядок

Уголовная политология. В сложившихся условиях кажется необходимым развитие уголовной политологии как самостоятельной науки, основанной на традициях российской правовой мысли. Развитие это должно происходить и основываться на теоретикоинструментальном подходе, сложившемся в системе уголовно-правовых наук. Наука уголовной политологии, как неоднократно подчеркивал профессор А.Э. Жалинский, должна восприниматься в качестве объекта реальных социальных процессов уголовной политики, взаимодействующие с целостным механизмом действия уголовного закона.

Развитие уголовной политологии как самостоятельной науки должно опираться на традиции российской уголовно-правовой науки с использованием теоретикоинструментального подхода, сложившегося в системе уголовно-правовых наук. В качестве непосредственного объекта наука уголовной политологии должна воспринимать объективные социальные процессы уголовной политики, взаимодействующие с целостным механизмом действия уголовного закона. Подобного определения объекта уголовной политологии, в частности, придерживался А.Э. Жалинский9 , указывая, что воздействие политики на уголовное право проявляется по трем основным направлениям:

1) Механизм действия уголовного закона и его легитимные репрессивные возможности часто используются в качестве инструмента политического влияния. При этом они могут быть направлены как на распределение политической власти (т.н. «пунитивный популизм»), так и на ее реализацию (проведение, осуществление).

2) Уголовное законодательство в каждый конкретный момент времени отражает сложившееся под влиянием политики отношение общества к правопорядку; политика при этом является важнейшим фактором, программирующим содержание уголовного закона.

3) Влияющие на механизм уголовного права политические позиции сами являются продуктом политической конкуренции; в условиях означенной конкуренции они могут противоречиво влиять на уголовное законодательство и проявляться в таких нежелательных формах, как уголовно-правовой нигилизм и популизм.

Но, несмотря на реально существующую тесную связь с публичной политикой, право вообще и уголовное право в частности до сих пор считается главным легитимирующим феноменом. Принято полагать, что общество стремится формировать право как нечто сво-

\footnotetext{
${ }^{9}$ См.: Жалинский А. Э. Уголовная политология: становление и
} развитие // Право и политика. 2010. № 5. С. 826-834. бодное от негативных явлений, а потому воспринимает публичное право как явление, наиболее адекватное существующим общественным нуждам, воплощающее максимальное общественное доверие. Но одновременно с этим, право является инструментом политики, гибко меняющимся под субъективные нужды превалирующих в определенный момент политических сил больше, чем под нужды общества.

Применение уголовного права влечет в определенном смысле куда более значимые последствия для общества и личности, чем применение иных правовых отраслей. Оно связано с жизненно важными интересами и представляет собой непосредственное осуществление власти в самом жестком виде - в виде запрета и насилия ${ }^{10}$. Именно поэтому необходимо разработать наиболее подходящую концепцию модернизации уголовного закона, основанную на потребностях быстро развивающегося современного общества. Для чего необходим комплексный анализ практики применения норм уголовного права, эффективности их использования, целесообразности и т.п. уголовного закона без отрыва от наиболее важных сфер человеческой и государственной деятельности.

\section{Библиография:}

1. Жалинский А.Э. Уголовное право в ожидании перемен: теоретико-инструментальный анализ. - М.: Проспект, 2008. С. 5.

2. Жалинский А.Э. Уголовное право. Т.1. Общая часть / Под ред. Д-р юрид. наук, проф., засл. деятеля науки РФ А.Э. Жалинского. - М.: Изд. Дом «Городец», 2011. - 864 c.

3. Кибальник, А. Г. Влияние международного уголовного права на российское уголовное право: Автореф. Автореф. дис.... канд. юрид. наук . 12.00.08. Институт государства и права Российской академии наук.-М.,2003.-52c.

4. Г.Ю. Лесников. Проблемы соотношения уголовной политики и уголовного права // Научные ведомости Белгородского государственного университета. Серия: Философия. Социология. Право. №4. 2008. C. 74.

5. Barysheva K. Ways of the modern criminal law development. Justitias Welt. Ausgabe 22, November 2013 http:// justitiaswelt.com/Aufsaetze/AS86_201311_KB.pdf

\footnotetext{
${ }^{10}$ Жалинский А.Э. Уголовное право в ожидании перемен: теоретико-инструментальный анализ. - М.: Проспект, 2008. С. 7.
} 
DOI: 10.7256/1811-9018.2013.12.10394

При цитировании этой статьи сноска на dоі обязательна

\section{Право и политика $12(167) \cdot 2013$}

6. Жалинский А. Э. Уголовная политология: становление и развитие // Право и политика. 2010. № 5. С. 826-834.

7. Н. И. Костенко Организация Объединенных Наций в развитии международной уголовной юстиции // Международное право и международные организации. - 2012. - 3. - С. $71-82$.

\section{References (transliteration):}

1. Zhalinskii A.E. Ugolovnoe pravo v ozhidanii peremen: teoretiko-instrumental'nyi analiz. - M.: Prospekt, 2008. S. 5.

2. Zhalinskii A.E. Ugolovnoe pravo. T.1. Obshchaya chast' / Pod red. d-r yurid. nauk, prof., zasl. deyatelya nauki RF A.E. Zhalinskogo. - M.: Izd. Dom «Gorodets», 2011. - 864 s.
3. Kibal'nik, A. G. Vliyanie mezhdunarodnogo ugolovnogo prava na rossiiskoe ugolovnoe pravo :Avtoref. Avtoref. dis.... kand. yurid. nauk . 12.00.08. Institut gosudarstva i prava Rossiiskoi akademii nauk.-M.,2003.-52s.

4. G.Yu. Lesnikov. Problemy sootnosheniya ugolovnoi politiki i ugolovnogo prava // Nauchnye vedomosti Belgorodskogo gosudarstvennogo universiteta. Seriya: Filosofiya. Sotsiologiya. Pravo. №4. - 2008. S. 74.

5. Barysheva K. Ways of the modern criminal law development. Justitias Welt. Ausgabe 22, November 2013 http://justitiaswelt.com/Aufsaetze/AS86_201311_ KB.pdf

6. Zhalinskii A. E. Ugolovnaya politologiya: stanovlenie i razvitie // Pravo i politika. 2010. № 5. S. 826-834.

7. N. I. Kostenko Organizatsiya Ob'edinennykh Natsii v razvitii mezhdunarodnoi ugolovnoi yustitsii // Mezhdunarodnoe pravo i mezhdunarodnye organizatsii. -2012 . -3 . - C. $71-82$. 